\title{
Population Behavior in the Mathematical Model of the Spread of COVID19 Type SEIRS
}

\author{
Asmaidi $^{\mathrm{a}, 1, *}$, Resky Rusnanda ${ }^{\mathrm{b}, 2}$ \\ ${ }^{a}$ Program Study of Geophysics, Faculty of Mathematic and Natural Sciences, Mulawarman University, Samarinda, \\ 75123, Indonesia \\ b Polytechnic of South Aceh, Merdeka Street, Komplek Reklamasi Pantai,Tapaktuan city, 23751, Indonesia \\ lasmedmat@fmipa.unmul.ac.id*; ${ }^{2}$ reskyrusnanda@gmail.com
}

\begin{tabular}{ll} 
ARTICLE INFO & ABSTRACT \\
\hline $\begin{array}{l}\text { Article history: } \\
\text { Accepted }\end{array}$ & Mathematical modeling utilized to simplify real phenomena that \\
& occur in everyday life. Mathematical modeling is popular to \\
& modeling the case of the spread of disease in an area, the growth of \\
& living things, and social behavior in everyday life and so on. This \\
& type of research is included in the study of theoretical and applied \\
& mathematics. The research steps carried out include 1) constructing a \\
& mathematical model type SEIRS, 2) analysis on the $S E I R S$ type \\
& mathematical model by using parameter values for conditions \\
& $\mathcal{R}_{0}<1$ land $\left.\mathcal{R}_{0}>1,3\right)$ Numerical simulation to see the behavior of \\
& the population in the model, and 4$)$ to conclude the results of the \\
& numerical simulation of the $S E I R S$ type mathematical model. The \\
& simulation results show that the model stabilized in disease free \\
& equilibrium for the condition $\mathcal{R} \mathcal{R}_{0}<1$ and stabilized in endemic \\
& equilibrium for the condition $\mathcal{R}_{0}>1$.
\end{tabular}

COVID19

SEIRS

\section{Introduction}

Simplification of real phenomena in everyday life can be expressed in Mathematical Language using an equation or a system of mathematical equations. This equation or system of equations is known as mathematical modeling. Mathematical modeling can be used to describe the behavior of individuals or populations in a model. For example, describing cases of the spread of disease in an area, the growth of living things, and human social behavior in daily life and so on.

Several mathematical modeling concepts are used to describe the phenomenon of a population in everyday life such as the research developed by [1] Numerical Solution of SIRS model for Dengue Fever Transmission in Makassar City with Runge Kutta Method. Next [2], Develop about The Analysis of SEIRS-SEI Epidemic Models on Malaria with Regard to Human Recovery Rate. In [3] Developed the SIR Mathematical Model as a Solution for Addiction to the Use of Social Medial. Furthermore [4], Discusses modeling the Use of E-Money in E-Parking in Makassar City. The concept of modeling is widely used for other fields of science.

In this article, a mathematical model of the SEIRS type of COVID19 spread is developed. SEIRS stands for Susceptible, Exposed, Infected, and Recovered. This means that in the model developed there is a susceptible population, namely a susceptible population to the Corona virus. The exposed population or latent population in which the corona virus is present in the body, but has not been 
able to infect other individuals or populations. Infected population is a population that has the corona virus in its body and can infect other populations. The recovered population is the population that recovers after being infected, but the population can become a vulnerable population again due to a decrease in the body's immune system. Based on the construction of the mathematical model, the behavior of each population in the model is then seen by doing a simulation. The simulation was carried out using certain parameters obtained from a literature review of journals on mathematical modeling of the spread of COVID19.

\section{Method}

The type of research developed is theoretical and applied mathematics. The stages carried out in this research include:

1. Construct a mathematical model of type SEIRS

a) Define the variables contained in the modeling and then the assumptions and parameters used to describe population behavior will be determined. The assumptions used in mathematical modeling are:

1) The birth rate is the same as the natural death rate;

2) Natural death rates exist in each population;

3) The death rate due to COVID19 is only found in the exposed and infected population;

4) The recovered population does not recover permanently, but can become a recovered population due to decreased body immunity.

b) Based on the defined variables and the assumptions used, a mathematical modeling of the spread of COVID19 of the SEIRS type is made which consists of a system of autonomous differential equations.

$$
\dot{x}=f(x), x \in \mathbb{R}^{n},
$$

with $f$ is the real-valued continuous function of $x$. The system of differential equations (1) is called an autonomous system of first-order differential equations, because $f$ does not contain an explicit $t$-value in it [5]

2. Perform analysis on the SEIRS type mathematical model by using parameter values for conditions $\mathcal{R}_{0}<1$ and $\mathcal{R}_{0}>1$.

a) Determine disease free equilibrium and endemic equilibrium

Disease free equilibrium contains exposed, infected, recovered populations equal to 0 , while endemic equilibrium contains exposed, infected, recovered populations that are not equal to 0 .

b) Determine the value of the basic reproduction number $\left(\mathcal{R}_{0}\right)$ using the next generation matrix G.

$$
G=F V^{-1}
$$

c) Perform stability analysis for each fixed point.

3. Perform numerical simulations on the SEIRS type mathematical model to see the behavior of the population in the model.

4. Summarizing the results of the numerical simulation of the SEIRS type mathematical model.

\section{Results and Discussion}

\section{A. Mathematical Model of Type SEIRS}

The results in this study are in the form of compartment diagrams for the spread of COVID19 type SEIRS, fixed points, basic reproduction numbers, analysis of fixed point stability, and numerical simulations to see population dynamics in the mathematical model of the spread of COVID19 type SEIRS. The results of the study are described as follows. 


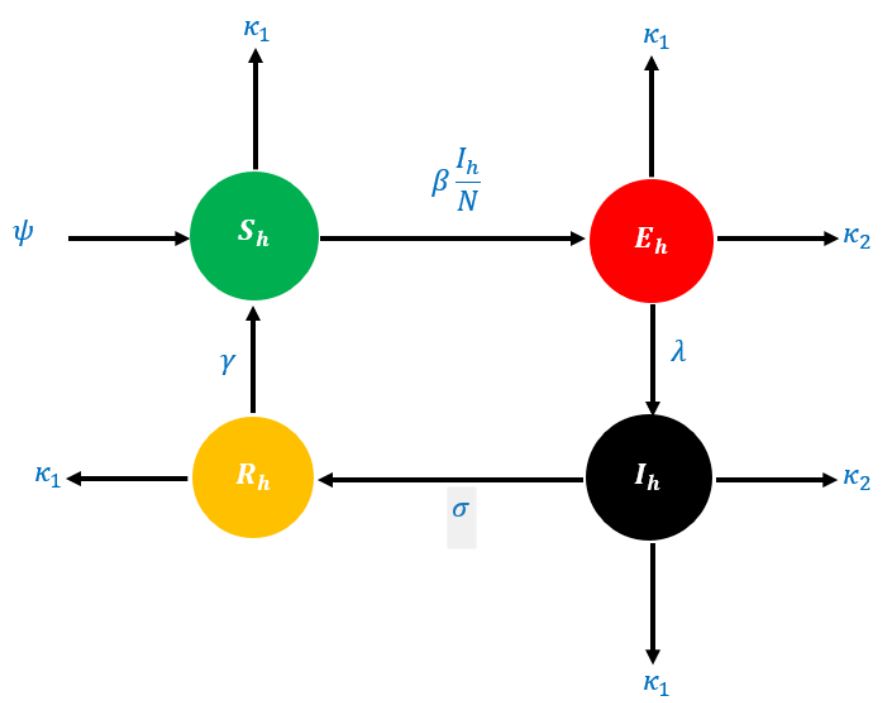

Figure 1. Mathematical Model of Type SEIRS

Based on this model, a system of differential equations is obtained:

$$
\begin{aligned}
\frac{d S_{h}}{d t} & =\psi+\gamma R_{h}-\left(\kappa_{1}+\beta \frac{I_{h}}{N_{h}}\right) S_{h} \\
\frac{d E_{h}}{d t} & =\beta \frac{S_{h} I_{h}}{N_{h}}-\left(\kappa_{1}+\kappa_{2}+\lambda\right) E_{h} \\
\frac{d I_{h}}{d t} & =\lambda E_{h}-\left(\kappa_{1}+\kappa_{2}+\sigma\right) I_{h} \\
\frac{d R_{h}}{d t} & =\sigma I_{h}-\left(\kappa_{1}+\gamma\right) R_{h}
\end{aligned}
$$

where $S_{h}+E_{h}+I_{h}+R_{h}=N_{h}$.

The information and units regarding the parameters in the model in Figure 1 are explained as follows.

Table 1. Parameters and Units

\begin{tabular}{cll}
\hline Parameters & \multicolumn{1}{c}{ Description } & Units \\
\hline$\psi$ & Birth Rate & time $^{-1}$ \\
$\kappa_{1}$ & Natural mortality rate & time $^{-1}$ \\
$\kappa_{2}$ & Morbid by COVID19 & time $^{-1}$ \\
$\beta$ & Infected chance by COVID19 & no unit \\
$\lambda$ & Incubation rate & time $^{-1}$ \\
$\sigma$ & Recovery rate & time $^{-1}$ \\
$\gamma$ & Cured rate to susceptible & time $^{-1}$ \\
\hline
\end{tabular}

Furthermore, the system of differential equations (3) is simplified by making a comparison of each population in the model with the total population,

$$
S^{h}=\frac{S_{h}}{N_{h}} ; E^{h}=\frac{E_{h}}{N_{h}} ; I^{h}=\frac{I_{h}}{N_{h}} ; R^{h}=\frac{R_{h}}{N_{h}}
$$


So obtained equation:

$$
\begin{aligned}
& \frac{d S^{h}}{d t}=\frac{\psi}{N_{h}}+\gamma R^{h}-\left(\kappa_{1}+\beta I^{h}\right) S^{h} \\
& \frac{d E^{h}}{d t}=\beta I^{h} S^{h}-\left(\kappa_{1}+\kappa_{2}+\lambda\right) E^{h} \\
& \frac{d I^{h}}{d t}=\lambda E^{h}-\left(\kappa_{1}+\kappa_{2}+\sigma\right) I^{h} \\
& \frac{d R^{h}}{d t}=\sigma I^{h}-\left(\kappa_{1}+\gamma\right) R^{h}
\end{aligned}
$$

where $s+e+i+r=1$. Parameter values for condition $\mathcal{R}_{0}<1$ dan $\mathcal{R}_{0}>1$ which is as follows:

Table 2. Parameter Value

\begin{tabular}{cccc}
\hline Parameter & $\begin{array}{c}\text { Parameter value } \\
\text { for } \mathcal{R}_{0}<1\end{array}$ & $\begin{array}{c}\text { Parameter value } \\
\text { for } \mathcal{R}_{0}<1\end{array}$ & Source \\
\hline$\psi$ & 0.125 & 0.125 & \\
$\kappa_{1}$ & 0.125 & 0.125 & {$[6]$} \\
$\kappa_{2}$ & 0.017 & 0.017 & \\
$\sigma$ & 0.04 & 0.04 & \\
$\gamma$ & 0.01 & 0.01 & {$[7]$} \\
$\lambda$ & 0.2 & 0.4 & \\
$\beta$ & 0.000024 & 0.3 & \\
\hline
\end{tabular}

\section{B. Equilibrium and Static Points}

The results of data analysis carried out on the mathematical model of the spread of COVID19 using the parameters in Table 2, namely:

1) $\left(S_{0}^{h}, E_{0}^{h}, I_{0}^{h}, R_{0}^{h}\right)=(1,0,0,0)$ with value $\mathcal{R}_{0}=0.0089$;

2) $\left(S_{1}^{h}, E_{1}^{h}, I_{1}^{h}, R_{1}^{h}\right)=(0.822,0.041,0.091,0.027)$ with value $\mathcal{R}_{0}=1.1029$.

where $\left(S_{0}^{h}, E_{0}^{h}, I_{0}^{h}, R_{0}^{h}\right)$ disease free equilibrium and $\left(S_{1}^{h}, E_{1}^{h}, I_{1}^{h}, R_{1}^{h}\right)$ endemic equilibrium.

Furthermore, using the parameter values in Table 2, a numerical simulation is carried out to see the behavior of the population in the SEIRS type of COVID19 distribution mathematical model. The simulation results obtained the following results:

\section{Population Behavior}

1) Population Behavior to $\mathcal{R}_{0}<1$

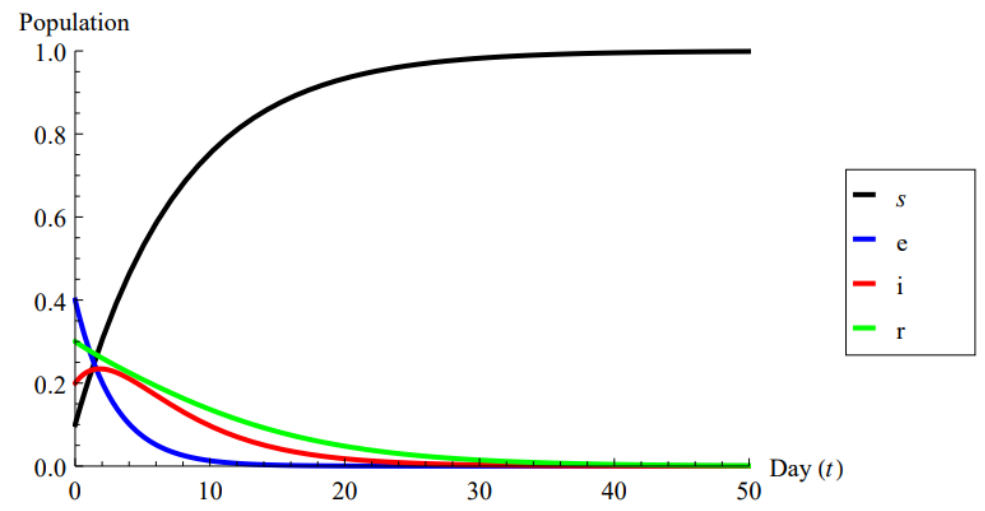

Figure 2. Population Behavior to $\mathcal{R}_{0}<1$ 
Based on the simulation results, it can be described that when $\mathcal{R}_{0}<1$ or $\mathcal{R}_{0}=0.0089$, susceptible population $\left(S^{h}\right)$ increases from the initial value and is stable around $S^{h}=1$. Exposed population $\left(E^{h}\right)$ decreases from the initial value and stabilizes around $E^{h}=0$. The infected population $\left(I^{h}\right)$ initially increases from the initial value then decreases and stabilizes around $I^{h}=0$. The recovered population $\left(R^{h}\right)$ drops from its initial value and stabilizes around $R^{h}=0$. Population in the mathematical model of COVID19 dispersion type SEIRS was stable around disease free equilibrium $\left(S_{0}^{h}, E_{0}^{h}, I_{0}^{h}, R_{0}^{h}\right)=(1,0,0,0)$.

\section{2) Population Behavior for $\mathcal{R}_{0}>1$}

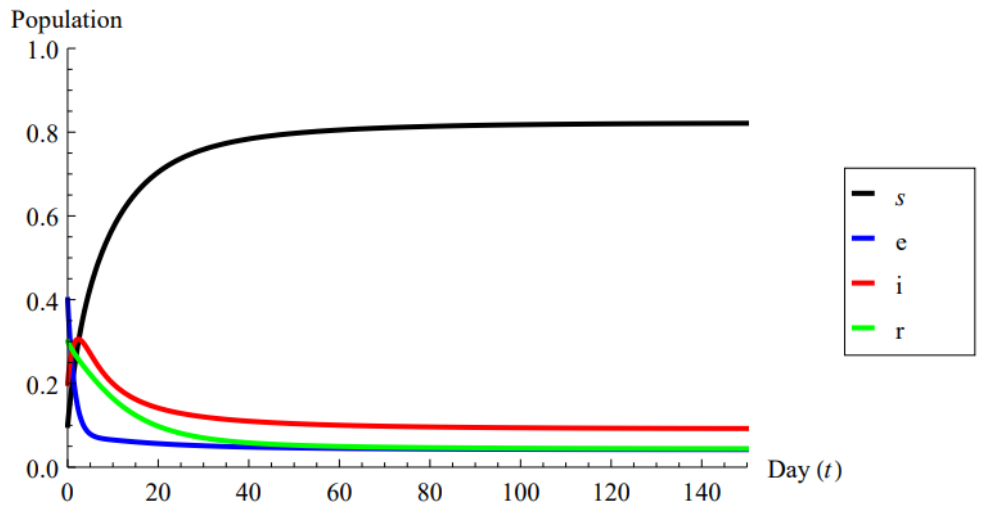

Figure 3. Population Behavior to $\mathcal{R}_{0}>1$

Based on the simulation results, it can be described that when $\mathcal{R}_{0}>1$ or $\mathcal{R}_{0}=1.1029$, susceptible population $\left(S^{h}\right)$ rose from the initial value and stabilized around $S^{h}=0.822$. The exposed population $\left(E^{h}\right)$ dropped from the initial value and stabilized around $E^{h}=0.041$. The infected $\left(I^{h}\right)$ initially rises from the initial value then decreases and stabilizes around $I^{h}=0.091$. The recovered group $\left(R^{h}\right)$ lowered from the initial value and stabilized around $R^{h}=0.027$. Population in the mathematical model of COVID19 dispersion type SEIRS was stable around endemic equilibrium $\left(S_{1}^{h}, E_{1}^{h}, I_{1}^{h}, R_{1}^{h}\right)=(0.822,0.041,0.091,0.027)$.

\section{Conclusion}

The simulation results using parameters as shown in Table 2 can be concluded that the behavior of the population in the mathematical model of the spread of COVID19 type SEIRS is stable around disease free equilibrium for conditions $\mathcal{R}_{0}<1$ when $\left(S_{0}^{h}, E_{0}^{h}, I_{0}^{h}, R_{0}^{h}\right)=(1,0,0,0)$ and stable around endemic equilibrium for condition $\mathcal{R}_{0}>1$ with $\left(S_{1}^{h}, E_{1}^{h}, I_{1}^{h}, R_{1}^{h}\right)=(0.822,0.041,0.091,0.027)$.

\section{Acknowledgment}

Thanks are extended to the friends in the Study of Geophysics Faculty of Mathematic and Natural Sciences Mulawarman University who have supported and provided assistance in completing this research.

\section{References}


[1] Side, S et al. 2021. Numerical solution of SIR model for transmission of tuberculosis by Runge-Kutta method. IOP Conf. Series: Journal of Physics: Conf. Series 1040 (2018) 012021. doi :10.1088/1742-6596/1040/1/012021. IOP Publishing.

[2] Resmawan, Sianturi S, Nugrahani EH. 2017. Develop about The Analysis of SEIRS-SEI Epidemic Models on Malaria with Regard to Human Recovery Rate. Aceh International Journal of Science and Technology. 6(3) ISSN: p-2088-9860; e-2503-2398 Desember 2017, doi: 10.13170/aijst.6.3. 9303: Aceh.

[3] Side S, Sanusi W, Rustan NK. 2020. Model Matematika SIR Sebagai Solusi Kecanduan Penggunaan Media Sosial. Journal of Mathematics, Computations, and Statistics (hal. 126 138) Vol. 3. No. 2, Oktober 2020. Universitas Negeri Makassar.

[4] Ihsan H, Side S, Wulandari E. Pemodelan Penggunaan E-Money Pada E-Parking Kota Makassar. Journal of Mathematics, Computations, and Statistics (hal. 88 - 96) Vol. 3. No. 2, Oktober 2020. Universitas Negeri Makassar.

[5] Tu PNV. 1994. Dynamical System: An Introduction with Applications in Economics and Biology. New York: Springer-Verlag.

[6] Afwan, M.I \& Helma. 2021. Pemodelan Matematika Penyebaran Penyakit Covid-19 dengan Menggunakan Model SIRS. UNPjoMath, 4(2), ISSN: 997 235516589, September 2021. Universitas Negeri Gorontalo.

[7] Alrabaiah, $\mathrm{H}$ et al. 2021. A comparative study of spreading of novel corona virus disease by ussing fractional order modified SEIR model. Alexandria Engineering Journal, Oktober 2020. Alexandria University. 